\title{
Students' Perceptions of Electronic Feedback as an Alternative to Handwritten Feedback: One University's Inquiry
}

\author{
Nanette Edeiken-Cooperman ${ }^{1} \&$ Carolyn L. Berenato ${ }^{1}$ \\ ${ }^{1}$ Department of Special Education, Saint Joseph's University, Philadelphia, PA, USA \\ Correspondence: Nanette Edeiken-Cooperman, Saint Joseph's University, Department of Special Education, \\ 5600 City Ave., Philadelphia, PA 19131, USA. Tel: 1-610-660-3208. E-mail: ncooperm@sju.edu
}

Received: October 24, 2013

Accepted: January 20, $2014 \quad$ Online Published: February 19, 2014

doi:10.5539/jel.v3n1p79

URL: http://dx.doi.org/10.5539/jel.v3n1p79

\begin{abstract}
This study explored the area of effective feedback and whether undergraduate students prefer electronic or handwritten feedback. In teacher training programs this determination has become crucial because of the escalation in the number of formative assessments replacing summative assessments. A mixed methodology design was completed that involved participants that were undergraduate students who were education majors enrolled in the spring of 2013. An online application of a survey was used for data collection that was composed of 29 close-ended questions and 4 open-ended questions. The survey's closed-ended questions referred to demographic information, as well as preference questions concerning feedback in the form of handwritten or electronic responses.

The researchers found that the participating undergraduate students who were either Elementary Education majors or double majors in Elementary Education and Special Education were equally split in their preference, with $50 \%$ preferring handwritten and 50\% preferring electronic feedback. In addition, the results consisted of four identified themes; personal, efficiency, legibility, and individualization. The striking conclusion was that students reported overwhelmingly that handwritten feedback was preferred because it gave them the ability to establish a more personal rapport with their professors.
\end{abstract}

Keywords: electronic feedback, handwritten feedback, teacher training programs, mixed methodology

\section{Introduction}

Effective feedback, either electronic or personal, is a valued component of curriculum and instruction in higher education. "Although it is a frequently used term, feedback does not have clarity of meaning" (Price, Handley, Millar, \& O’Donovan, 2010, p. 278). It can be broadly defined as information that is provided to a student by a professor or instructor that indicates to that student their level of performance on an assignment/assessment. Denton, Madden, Roberts, and Rowe (2008) supplement that definition by adding that "feedback is that which indicates to learners where they have done well, where their misunderstandings are, and what follow-up work might be required" (p. 487). Shute (2008) adds that feedback is "information communicated to the learner that is intended to modify his or her thinking or behavior for the purpose of improving learning" (p. 154). It is generally delivered to the student in the form of written comments about an assignment/assessment, email, electronic notes on assignments, or other electronic formats offered by the specific Learning Management System. According to Price et al. (2010), feedback falls "broadly into five, but not entirely delineated discrete, categories: correction, reinforcement, forensic diagnosis, benchmarking and longitudinal development (feed forward)" (p. 278).

The quality and effectiveness of this feedback is essential to promote the learning process of the student and to indicate whether the student has adequately met the professor's goals and expectations of that assignment/assessment. Hattie and Timperley (2007) state, "When feedback is combined with more a correctional review, the feedback and instruction become intertwined" (p. 82) until "the process itself takes on the forms of new instruction, rather than informing the student solely about correctness" (Kulhavy, 1977, p. 212). Feedback should then provide information specifically relating to what was understood by the student and what the professor's goal of what should be understood by the assignment/assessment. Shute (2008) emphasizes that good feedback can improve learning processes and outcomes" but that this feedback must be "delivered correctly" in order to accomplish this result (p. 154). 
The aim of this study was to investigate the preference of undergraduate students who are majoring in either Elementary Education and/or Special Education in receiving feedback on their assignments/assessments and their perceptions of feedback as a tool to facilitate learning and improvement on future assignments. With the escalation in the number of formative assessments replacing summative assessments in teacher training programs, it has become crucial to determine which type of feedback, electronic or personal, is more effective and which do students prefer. Although there has been significant research completed concerning feedback, there has been minimal research from the student's point of view (Budge, 2011; Budge \& Gopal, 2009; Higgins, Hartley, \& Skelton, 2002; Murtagh \& Baker, 2009; Rowe \& Wood, 2008; Weaver, 2006). According to Rowe and Wood (2008), although feedback constitutes a central aspect of learning, current educational research has not focused on feedback as a primary issue, particularly from the student's perspective. This perspective could further inform professors in order to assist them in the facilitation of the learning process.

\section{Methods}

This study invited 236 undergraduate students from the Education Unit at a private, coeducational, Roman Catholic Jesuit university to take part in an investigation of the student's preference for either handwritten or electronic feedback and their rational for this preference. According to Chang et al. (2012), using a mixed methodology research design is a sound way to obtain different data on student perceptions pertaining to handwritten or electronic feedback. The mixed methodology approach combines the differing strengths and weaknesses of the quantitative methods with those of qualitative methods (Chang et al., 2012, p. 5). To best understand the research problem, a mixed methodology approach was used in this study, combining the differing strengths and weaknesses of quantitative methods examining the sample size, trends, and generalization with those of qualitative methods in the form of a questionnaire.

\section{Participants}

The participants were 236 undergraduate students who were education majors enrolled in the spring of 2013. Forty-two students responded, making the return rate $18 \%$. Out of the 42 respondents, 0 did not complete all of the survey questions. The survey sample total number of 42 participates resulted in a response rate of $100 \%$. The majority of the participants were juniors and seniors, 29 participants, with a $69 \%$ response rate. The freshman and sophomores totaled 13 participants with a $31 \%$ response rate.

Among the 42 participants, $100 \%$ were females, while $0 \%$ was males. Of the participants $100 \%$ were ranging from 18-22 years of age. Sixty seven percent of the participants indicated that their GPA was in the 3.5-4.0 range. Thirteen students reported a GPA range of 3.0-3.4 and one student reported a 2.5-2.9 GPA range. Over half of the students surveyed, $57 \%$, were double majors of elementary and special education, while $43 \%$ were elementary majors.

\section{Instrument}

An online application of a survey was used for data collection. The survey questions were developed by the two researchers and member checked by a faculty member with expertise in instructional technology. The survey instrument was sent anonymously from the registrar's office to the participants. The survey instrument format was composed of 29 close-ended questions and 4 open-ended questions. The survey's closed-ended questions asked about demographic information, as well as preference questions concerning feedback in the form of handwritten or electronic responses. The survey's four open ended questions were as follows: 1) Please define ELECTRONIC feedback below and then provide one example to help us understand it better. DEFINITION, EXAMPLE, 2) I use the professor's feedback in order to improve on my further assignments, 3) The professor's feedback is not helpful on future assignments. TRUE, FALSE, 4) Do you have any other comments to make about assessment or assessment feedback that may help the faculty to better facilitate your learning?

\section{Procedure}

Two months after the spring semester of 2013 started, all undergraduates admitted into the Teacher Education and Special Education preparation programs were invited to participate in the study via their university email. The University's registrar's office sent the potential participants to a prompt on an online site with a consent letter that informed them of the purpose of the study, ensured confidentiality, and that participation in the study was voluntary. If the potential respondents agreed to participate, they continued on to complete the survey. The survey was available directly in the student's email account. The participants had to respond to all questions and the data was collected anonymously. 


\section{Results}

Students were requested to give personal data that included gender, age, current class standing, current grade point average (GPA), and major within the Education Unit located in the College of Arts and Sciences. Table 1 displays that all of the respondents were female and the distribution of class standing was $14.29 \%$ freshmen, $16.67 \%$ sophomores, $47.62 \%$ juniors, and $21.43 \%$ seniors. All students were either elementary education majors or double majors in elementary education and special education with $14.29 \%$ as elementary education majors and $85.71 \%$ as double majors as indicated in table 2 . A majority of the students reported a GPA range of 3.5 to $4.0,66.67 \%$, and the remaining GPAs fell between the 2.5 to 3.4 range as seen in table 2 .

Table 1. Demographic information

\begin{tabular}{llll}
\hline Variables & Types & Number & Percentage \\
\hline \multirow{3}{*}{ Gender } & Male & 0 & $0 \%$ \\
& Female & 42 & $100 \%$ \\
& & & \\
\multirow{3}{*}{ Academic Class } & Freshman & 6 & $14.29 \%$ \\
& Sophomore & 7 & $16.67 \%$ \\
& Junior & 20 & $47.62 \%$ \\
& Senior & 9 & $21.43 \%$ \\
\hline
\end{tabular}

Table 2. Academic information

\begin{tabular}{llll}
\hline Variables & Types & Number & Percentage \\
\hline \multirow{3}{*}{ Major } & Elementary & 6 & $14.29 \%$ \\
& Spec Ed/Elementary & 36 & $85.71 \%$ \\
& Secondary & 0 & $0 \%$ \\
& Undeclared & 0 & $0 \%$ \\
& & \\
GPA Range & $3.5-4.0$ & 28 & $66.67 \%$ \\
& $3.0-3.4$ & 13 & $30.95 \%$ \\
& $2.5-2.9$ & 1 & $2.58 \%$ \\
& Below 2.5 & 0 & $0 \%$ \\
\hline
\end{tabular}

Responses to the survey were recorded within Survey Monkey and then nonparametric tests were utilized along with an analysis of qualitative responses. Three researchers read and analyzed the respondents' responses and identified themes. Four themes were identified: timeliness or efficiency (E), legibility (L), personal (P), and individualization (I). Once the coders further defined the themes, the researchers then checked the codes for reliability.

In response to the question "Please define electronic feedback below and then provide one example," students were in agreement that this referred to receiving feedback either on Blackboard9, the learning management strategy currently in use at this University, or by email. Examples referenced receiving comments, grades, or completed rubrics attached to the assignment being graded.

The percentage of the students that preferred electronic feedback, $50 \%$, or handwritten feedback, $50 \%$, was exactly equal. This was also the case in response to "this type of feedback allows for revisions and improvements on assignments." The students overwhelmingly agreed that it is easier to establish a rapport with their professor with handwritten feedback, $69.05 \%$, as opposed to $30.95 \%$ as seen in table 3 . In addition, table 3 indicates that students felt as though they were encouraged to read feedback when it was handwritten, $71.43 \%$, rather than the $28.57 \%$ that were encouraged by electronic feedback. Students believed that when they received handwritten 
feedback the professors cared about them and the other students, $73.81 \%$, and that they appreciated the professor's time and attention with handwritten feedback as well, $83.33 \%$, also exemplified in table 3 .

Table 3. Responses to closed ended questions

\begin{tabular}{llll}
\hline Question & Type of Feedback & Number & Percentage \\
\hline What kind do you prefer? & Electronic & 21 & $50 \%$ \\
& Handwritten & 21 & $50 \%$ \\
$\begin{array}{l}\text { Allows me to establish rapport } \\
\text { with my professor }\end{array}$ & Electronic & 13 & $30.95 \%$ \\
& Handwritten & 29 & $69.05 \%$ \\
$\begin{array}{l}\text { This feedback shows } \\
\text { professor cares }\end{array}$ & Electronic & 11 & $26.19 \%$ \\
$\begin{array}{l}\text { This feedback make } \\
\text { appreciate my professor's time } \\
\text { and attention }\end{array}$ & Handwritten & 31 & $73.81 \%$ \\
& Handwritten & 7 & $16.67 \%$ \\
$\begin{array}{l}\text { This feedback encourages me } \\
\text { to read the feedback }\end{array}$ & Electronic & & $83.33 \%$ \\
\hline
\end{tabular}

\section{Discussion}

This study established in response to the question of whether the undergraduate students at this particular university preferred electronic or handwritten feedback, that $50 \%$ of the participating undergraduate students preferred handwritten and 50\% preferred electronic. The striking conclusion was that students reported the ability to establish a rapport with their professor with handwritten feedback, $69.05 \%$, as opposed to $30.95 \%$. As well as the students believed that when they received handwritten feedback, $71.43 \%$, the professor encouraged them to read the feedback as opposed to $28.57 \%$. Lastly the students reported the type of feedback that made them appreciate the professor's time was handwritten feedback, $83.33 \%$, as opposed to $16.67 \%$ electronic feedback. In the following, the resulting four identified themes of personal, efficiency, legibility, and individualization are discussed.

\subsection{Themes}

\subsubsection{Personal}

In this study personal refers to the actual preference of handwritten feedback. Handwritten feedback appears to allow for establishing a closer rapport with the professor. One student noted, "If they (professor) take the time to write it (feedback), I can take the time to consider it (feedback) for my next assignment." Another student noted, "I usually prefer handwritten feedback on the hard copies of assignments I hand in. "It's especially useful when the professor actually makes notes throughout an essay or paper." These findings are supported by Chang et al. (2012) who state, "some students still feel a strong dislike toward e-feedback" (p. 12). Chang et al. also stated that "asking professors questions in person, from the perspectives of the handwritten feedback supporters, was an avenue to establish a relationship with a professor" (p. 12). 


\subsubsection{Efficiency}

In this study efficiency refers to timeliness. Most participants noted that they were able to receive electronic feedback effortlessly, but often students mentioned comments needed to be included. Students noted they were looking for constructive comments as well as positive comments. One student reported, "I appreciate the timeliness of teachers' comments electronically, they (professors) need to put positive comments." Another student wrote, "Although electronic feedback is easier and more efficient for many to write and read, handwritten feedback is more personal and creates a sense of care from teacher to students." Budge (2011) purports, electronic feedback is viewed as "not human enough" in student descriptions (p. 347). The importance of a personal connection was evident in the findings between the professor and the student. Price and Donovan (2007) support the need for a more personal approach and for feedback to be considered in the broad context of student learning, not just for a single assignment.

\subsubsection{Legibility}

In this study legibility refers to the ease of reading the professor's comments on an assignment. An example of the students' responses in reference to legibility was "Electronic feedback is not only easier to read but also more convenient for while you can lose the only paper copy, online copies are endless when the document is uploaded to Blackboard." Another student indicates that electronic feedback is "sometimes more timely and easier to read" and an additional student agrees with this statement by saying "electronic feedback is easier and more efficient for many to write and read." According to Ferguson (2011), "a surprisingly large number of students reported difficulty reading written responses from staff' (p. 55).

It is essential to determine the clarity of purpose of providing feedback in order to determine the relevance of legibility. Price et al. (2010) state that "increasingly, the popular view is that feedback must explicitly address future activity" therefore the focus should be on including "feedback directed at supporting improvements in the next assignment," but also on providing guidance for "longitudinal development" (p. 279). Therefore, the student should closely align the ease of reading and understanding feedback to the appropriate use of feedback.

\subsubsection{Individualization}

Students responded that instructors should not give the same feedback to each student. One student expressed that "feedback should be individualized to each student as all students are unique." Another student expressed that it was helpful when the instructor shared "both positive and constructive criticism in an email response." A majority of students agreed that feedback was essential when trying to improve on future assignments, but that each individual student required a different type of feedback that was dependent on the individual needs of a particular student and their style of learning. Hattie and Timperley (2007) state, "that to be powerful in its effect, there must be a learning context to which feedback is addressed" (p. 82). It has also been reported that students "value the detail in feedback on their work, regardless of the form in which it was given" (Budge, 2011, p. 347). Individualization of feedback provides an opportunity for the student to not only focus on correction of future assignments or receiving a better grade, but to reflect on the meaning of the assignment and concepts that have been learned.

\section{Conclusion}

Feedback, as defined in this article, is information that is provided to a student by a professor or instructor that indicates to that student their level of performance on an assignment/assessment. Although the response to the preference for electronic versus handwritten feedback was split equally, the students that completed this survey reported overwhelmingly that handwritten feedback was more personal and gave them the feeling that the professor cared about them as a student. Budge (2011) explained this outlook as follows:

The message here is that we cannot make assumptions about how students want to use technology in all aspects of their lives, including the learning environments in which they are engaged. Significantly, in this period of history where technology plays a central role in peoples' lives, there is a human aspect to feedback that is conveyed through non-electronic forms that students value very highly. (p. 348)

As educators in the higher education environment, it is essential to consider the best way to convey messages to our students that promote pedagogy. According to Weaver (2006), "It is accepted in academic circles that feedback is an essential component in the learning cycle" (p. 379). Therefore, we have a responsibility to determine which type of feedback is most effective based on how that feedback is used without interjecting emotions into the equation. Hattie and Timperley (2007) stated, "feedback needs to be clear, purposeful, meaningful, and compatible with students' prior knowledge and to provide logical connections" (p. 104). In the true context of pedagogy, this should be efficient and timely in order to give the student an opportunity to reflect 
and apply the corrections that have been indicated in the feedback. Our goal should be to interweave feedback with the instructional process in order to provide the scaffolding that is necessary to learn.

\section{Limitations and Recommendations}

The primary consideration when determining the limitations of this study was that the gender of all of the respondents was the same. This factor was a coincidence, but could possibly be controlled by determining through university documents the number of male and/or female students that are within the population of the specific program being studied. Although all respondents were female, this does not diminish the fact that this study provided results that should be considered in the higher education environment. Another limitation of the study is that it was conducted in a single university; caution should be taken in the generalization in its findings to other universities that lead to the importance of future research.

Further research of the present study could be replicated and expanded to include undergraduate students and graduate students. Since the issue of feedback is universal in higher education, the present study could be replicated and expanded to other universities. The focus of future research should expand on the concept of electronic feedback and determine how to improve this feedback so that it can be converted into a feed-forward experience, rather than simply stagnant feedback. Students should have the opportunity to not only improve on their next assignment, but to absorb a professor's feedback to the extent that it becomes a critical factor in the learning process.

\section{References}

Budge, K. (2011). A desire for the personal: Student perceptions of electronic feedback. International Journal of Teaching and Learning in Higher Education, 23(3), 342-349.

Budge, K., \& Gopal, S. (2009). Feedback: Working from the student perspective. Proceedings of the Assessment in Different Dimensions, AT Assessment Conference, Melbourne, Australia.

Chang, N., Watson, A. B., Bakerson, M., Williams, E. E., McGoron, F. X., \& Spitzer, B. (2012). Electronic feedback or handwritten feedback: What do undergraduate students prefer and why? Journal of Teaching and Learning with Technology, 1(1), 1-13.

Denton, P., Madden, J., Roberts, M., \& Rowe, P. (2008). Students' response to traditional and computer-assisted formative feedback: A comparative case study. British Journal of Educational Technology, 39(3), 486-500. http://dx.doi.org/10.1111/j.1467-8535.2007.00745.x

Hattie, J., \& Timperley, H. (2007). The power of feedback. Review of Educational Research, 77(1), 81-112. http://dx.doi.org: 10.3102/003465430298487

Higgins, R., Hartley, P., \& Skelton, A. (2002). The conscientious consumer: Reconsidering the role of assessment feedback in student learning. Studies in Higher Education, 27(1), 53-64. http://dx.doi.org/10.1080\%2F03075070120099368

Kulhavy, R. W. (1977). Feedback in written instruction. Review of Educational Research, 47(1), 211-232.

Murtagh, L., \& Baker, N. (2009). Feedback to feed forward: Student response to tutors' written comments on assignments. Practitioner Research in Higher Education, 3(1), 20-28.

Price, M., \& Donovan, B. (2007). Making meaning out of assessment feedback-getting more than the message. Proceeding of the HERDSA conference, Adelaide, Australia.

Price, M., Handley, K., Millar, J., \& O’Donovan, B. (2010). Feedback: All that effort, but what is the effect?

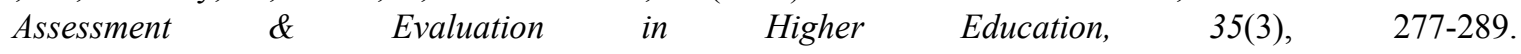
http://dx.doi.org/10.1080/02602930903541007

Rowe, A. D., \& Wood, L. N. (2008). Student perceptions and preferences for feedback. Asian Social Science, $4(3), 78-88$.

Shute, V. J. (2008). Focus on formative feedback. Review of Educational Research, 78(1), 153-189. http://dx.doi.org/10.3102\%2F0034654307313795

Weaver, M. R. (2006). Do students value feedback? Student perceptions of tutors' written responses. Assessment and Evaluation in Higher Education, 31(3), 379-394. http://dx.doi.org/10.1080\%2F02602930500353061 


\section{Copyrights}

Copyright for this article is retained by the author(s), with first publication rights granted to the journal.

This is an open-access article distributed under the terms and conditions of the Creative Commons Attribution license (http://creativecommons.org/licenses/by/3.0/). 